\title{
Teaching about Sexual Minorities: An lowa Experience
}

\author{
Veronika E. B. Kolder, M.D. ${ }^{1}$, Nashae Y. Julian, M.S. Ed. ${ }^{2}$
}

Key Words: Attitude of health personnel; health knowledge, attitude, practice; minority groups; homosexuality; teaching; lowa

\begin{abstract}
Despite greater social acceptance of sexual minorities and growing national support for equal medical care, disparities in healthcare access persist. Medical school curricula allot limited time to sexuality education and students' perceptions. Combining the topics of sexual response and sexual minority healthcare may perpetuate the misconception that lesbianism and transgender identity are deviations from normal sexual functioning. We comment on teaching about sexual minority healthcare at our medical school and argue for a review of medical educator preparation and existing curricula.

${ }^{1}$ Department of Obstetrics and Gynecology, Carver College of Medicine, University of lowa Hospitals and Clinics, ${ }^{2}$ Counseling, Rehabilitation, and Student Development, College of Education, University of lowa

Financial and funding disclosures: none
\end{abstract}

Acknowledgement of financial support: none
Greater social acceptance has changed how sexuality and reproduction are discussed within the medical community. ${ }^{1}$ Still, disparities in medical access persist for sexual minorities. To cite an example, lesbians may have access to self-help literature about conception $^{2,3}$ and usually seek the help of a general gynecologist or reproductive endocrinologist when they hope to conceive. However, most gynecologists do not provide donor insemination for lesbians and are unwilling to deal with the unique insurance and legal issues associated with serving this population. While the refusal of services to lesbians would be considered unethical in most professions, the American Medical Association (AMA) has long upheld the principle of 'provider conscience'. According to the AMA code of medical ethics, "A physician shall, in the provision of appropriate patient care, except in emergencies, be free to choose whom to serve..." 4

Please cite this paper as: Kolder VEB, Julian NY. Teaching about Sexual Minorities : an lowa Experience. Proc Obstet Gynecol. 2010 Apr;1(1):Article 10 [5 p.]. Available from: http://ir.uiowa.edu/pog/vol1/iss1/12/. Free full text article.

Corresponding author: Veronika E. B. Kolder, M.D., Department of Obstetrics and Gynecology, University of lowa, 51221 PFP, 200 Hawkins Drive, lowa City, IA 52242. Telephone (319) 384-8640, fax (319)384-8620, veronika-kolder@uiowa.edu 
There is growing national support for inclusion of lesbian, gay, bisexual, and transgender (LGBT) issues in discussions of medical cultural competency and equal access to healthcare. In 2008, the Joint Commission supported inclusion by appointing the executive director of the Gay and Lesbian Medical Association (GLMA), the largest professional organization for gay and lesbian healthcare providers, to its Expert Advisory Panel on Developing Hospital Standards for Culturally Competent Patient-Centered Care. ${ }^{5,6}$

Support for equal access came from the Obama administration when it started the process of repealing the Department of Health and Human Services' 'provider conscience' rules. ${ }^{6}$ Though primarily abortion-related, the Bush administration rules had been written so broadly that they carried the potential to impair sexual minority patients' access to basic healthcare services. ${ }^{7}$ The AMA and the American College of Obstetricians and Gynecologists (ACOG) were among dozens of medical organizations that had already urged the Bush administration to withdraw its conscience rules before they were finalized. ${ }^{8}$

A 2007 ACOG ethics committee opinion cogently addressed the limits of conscientious refusal in reproductive healthcare. It emphasized the need to avoid discrimination when considering requests to provide infertility services to same-sex couples. Beyond the insult of refusing services, it cautioned that "allowing physicians to discriminate on the basis of sexual orientation would constitute a deeper insult, namely reinforcing the scientifically unfounded idea that fitness to parent is based on sexual orientation, and, thus, reinforcing the oppressed status for same-sex couples". 9

Additional landmarks in the struggle for healthcare equity include recent statements by two national medical organizations. In October of 2009, the Ethics Committee of the American Society for Reproductive Medicine reaffirmed its past position on equal treatment of sexual minorities stating that "there is no persuasive evidence that children raised by single parents or gays and lesbians are harmed or disadvantaged by that fact alone". The committee recommended that all requests for assisted reproduction be treated equally. ${ }^{10}$ Then, in November of 2009, the AMA passed resolutions against the military's 'don't ask, don't tell' policy and criticizing bans on same-sex marriage, stressing their impact on healthcare disparity. ${ }^{11}$

Within institutions that provide reproductive services to sexual minorities, education regarding LGBT healthcare may be limited. Our University of lowa is an example of a large institution that has expanded reproductive services to include sexual minorities. Services were made available to lesbian couples in 2002 and to single women regardless of sexual orientation in 2007. Gestational carrier services, an option for gay men, became available in 2009. While services have expanded, it appears to the best of our knowledge that no formal education for clinical staff or curriculum changes for medical students regarding the reproductive care of sexual minorities accompanied these modified practices. 
LGBT activists in the medical professions have often led advances in the care of sexual minority patients and medical education on LGBT issues. GLMA's mission is "to ensure equality in health care for lesbian, gay, bisexual and transgender individuals and health care providers". ${ }^{12}$ The organization's educational materials, provider guidelines, and networking opportunities empower LGBT medical professionals and improve the care of sexual minority patients. The 2009 annual GLMA conference included four sessions dedicated to medical education (annualconference@glma.org,

"Educational Track at GLMA Annual Conference", email message to first author, September 2009).

In our experience, collaboration improves the teaching of these difficult matters of sexuality and gender. The second author's training and skill in guiding classroom discussions on LGBT issues has informed the first author's teaching. Together we developed case studies that highlight individualized rather than stereotype-based care of sexual minority people. We emphasized that in order to provide culturally competent care, the unique historical, legal, societal, and financial factors that frame sexual minority experience need to be acknowledged. We have supplemented facts that correct common misconceptions and have sought to bring a social justice perspective to this aspect of medical education. Reflecting upon student's needs has led us to review the current curriculum and consider ways it might be improved.

Medical education is ripe for collaboration with other educators, particularly those with specialized knowledge of LGBT issues. Many medical educators have little training in teaching, communication skills, or counseling. They may sometimes be assigned to give lectures that cover sexual minority healthcare because of our own sexual orientation or stance within the departmental hierarchy, rather than any specific expertise in the field. Furthermore, educators have only a limited number of pertinent teaching materials to choose from. In presenting their medical school curriculum innovation for teaching about LGBT issues, Kelley, et al. noted that only three innovations, including their own, had been published since $1998 .^{13}$ None of the past innovations suggested learning from those with specialized knowledge about LGBT issues. ${ }^{13,14,15}$

The medical school curriculum at the University of lowa addresses LGBT healthcare during both the preclinical and clinical years. Second year students receive two 50-minute lectures devoted to LGBT patients. In addition, they receive two 50-minute lectures that touch on LGBT issues, one on sexual history taking and one on religion and sexuality. Neither lecture discusses the origins of sexual orientation and gender identity. Nationally, the Association of Professors of Gynecology and Obstetrics (APGO) publishes guidelines for preclinical medical student education related to our specialty. These guidelines do not include LGBT related biochemistry or genetics. ${ }^{16}$

During the clinical years of medical school, students may have some exposure to formal education related to LGBT patient care while they rotate through family practice, psychiatry, and/or obstetrics and gynecology. APGO educational 
objectives include a unit on human sexuality. ${ }^{17}$ At the University of lowa, Dr. Kolder's lecture, "Sexuality and Modes of Sexual Expression", is based on an APGO outline and is delivered to third year medical students during a 40minute lunch period. The lecture centers around five cases and touches on the physiology and endocrinology of sexual arousal as well as lesbian and transgender gynecological care.

While observing one of $\mathrm{Dr}$. Kolder's lectures, the second author noticed that medical students were quick to resist her over issues of sexual orientation. One student challenged the legitimacy of biological determinants of sexual orientation. Another student stated that sexual identity is defined by behavior and insisted on relating sexual behaviors of prisoners to that of selfidentified lesbians within mainstream society. Clearly the pre-clinical education of these students had not corrected fundamental misconceptions and stereotypes related to sexual minorities. Because of the limited time allotted, Dr. Kolder was unable to facilitate further discussion of these issues during the session.

Beyond the time constraints, we feel that the curriculum itself may contribute to student confusion. Yoking the topic of sexual response, which is a universal human function, to the topic of sexual minority healthcare may perpetuate the misconception that LGBT identities are deviations from normal sexual functioning.

Our teaching experience suggests that medical educators need help in identifying their own weaknesses and blind spots. The support, perspective, and expertise provided by an observer with specialized knowledge about LGBT issues can substantively improve teaching. Reflection upon the needs of students raised questions about LGBT curriculum content and highlighted places where the curriculum itself might be contributing to confusion. We find that the increasing social acceptance of sexual minorities can provide an opportunity for medical schools to review instructor preparation and current curricula.

\section{References}

1. Perrin EC, Cohen KM, Gold M, Ryan C, Savin-Williams RC, Schorzman CM. Gay and lesbian issues in pediatric health care. Curr Probl Pediatr Adolesc Health Care. 2004;34(10):355-98.

2. Mohler M, Frazer L. A Donor Insemination Guide: Written By and For Lesbian Women. New York, NY: Harrington Park Press; 2002.

3. Pepper R. The Ultimate Guide to Pregnancy for Lesbians. San Francisco, CA: Cleis Press Inc.; 2005

4. American Medical Association. http://www.ama-

assn.org/ama/pub/physicianresources/medical-ethics/code-medicalethics/principles-medical-ethics.shtml. Updated June 17, 2001. Accessed December 14, 2009.

5. Ginsberg, J. Biography. Gay Lesbian Medical Association. http://www.glma.org/index.cfm?fuseaction =page.viewPage\&PageID=698\&d:ICFusio nMX7|veritylDataldummy.txt. Accessed December 8, 2009.

6. Schneider J, Solmonese J. Letter from human rights campaign foundation president Joe Solmonese and GLMA president Jason Schneider. http://www.hrc.org/documents/Healthcare Equality Index 2009.pdf. Updated 2009. Accessed December 1, 2009. 
7. Stein, R. Obama to rescind provider conscience regulation. Talk of the Nation. National Public Radio. http://www.npr.org/templates/story/story.p hp?storyld=101349857. Updated March 2, 2009. Accessed December 1, 2009.

8. American Medical News. Ending abortion conscience rule? http://www.amaassn.org/amednews/2009/03/23/arsa0323 .htm. Updated March 23, 2009. Accessed December 18, 2009.

9. Committee on Ethics, American College of Obstetrics and Gynecology Committee Opinion. The limits of conscientious refusal in reproductive medicine. http://www.acog.org/from home/publicatio ns/ethics/c0385.pdf. Updated November 2007. Accessed December 15, 2009.

10. The Ethics Committee of the American Society for Reproductive Medicine. Access to fertility treatments by gay, lesbian, and unmarried persons. Fertil Steril. 2009;92:1190-1193.

11. Hensley S. AMA broadens its social agenda.

http://www.npr.org/blogs/health/2009/11/w hat is the ama.html. Updated November 12, 2009. Accessed December 7, 2009.

12. Gay and Lesbian Medical Association. http://glma.org/index.cfm?fuseaction=Pag
e.viewPage\&pageld $=532 . \quad$ Accessed December 8, 2009.

13. Kelley L, Chou CL, Dibble SL, Robertson PA. A critical intervention in lesbian, gay, bisexual, and transgender health: knowledge and attitude outcomes among second-year medical students. Teach Learn Med. 2008;20(3):248-53.

14. McGarry K, Clarke J, Cyr M, Landau C. Evaluating a lesbian and gay health curriculum. Teach Learn Med. 2002; 14:244-8;

15. Sack S, Drabant B, Perrin E. Communicating about sexuality: An initiative across the core clerkships. Academic Medicine 2002; 77:1159-60.

16. Association of Professors of Gynecology and Obstetrics. Prerequisites to a clerkship in obstetrics and gynecology: A guide for preclinical educators. Copyright 2005, APGO, 2130 Priest Bridge Drive, Suite \#7, Crofton, MD 21114.

17. Association of Professors of Gynecology and Obstetrics. APGO medical student educational objectives, $8^{\text {th }}$ edition. Copyright 2004, APGO, 2130 Priest Bridge Drive, Suite \#7, Crofton, MD 21114. 